\title{
Um cenário para a crioulização sem pidginização
}

\author{
Hildo Honório do Couto \\ Universidade de Brasília
}

\section{Abstract}

Taking the "principles of historical phonology" - formulated in the 30 s by Jakobson - as a starting point, my aim in this article is to show that the traditional "life-cycle" model of creole grammar formation is not the best one. It presupposes the problematic concepts of pidgin and nativization. I show that a better alternative would be to consider that creole grammar is formed when the mixed medium of interethnic communication resulting from the contact of mutually unintelligible languages becomes the primary language of the emerging community. Therefore, communalization is more important than nativization. Additionally, I show that the processes which occur in creole formation are very common elsewhere. 


\section{INTRODUÇÃO}

questão fundamental dos estudos crioulos é a formação e A transformação da gramática crioula. Todas as demais questões 1 atinentes à crioulística (outro nome para "estudos crioulos") convergem para ela. Por "formação da gramática crioula" deve entender-se não apenas a história imanente de formação das estruturas da gramática emergente, mas também as condições sócio-históricas em que isso se deu. Não se deve observar apenas a formação do novo código que permite a comunicação entre um emissor e um receptor na nova sociedade. Na verdade, "é a história sociolingüística dos falantes, e não a estrutura de sua língua, que constitui o principal fator determinante dos resultados lingüísticos do contato de línguas. Fatores puramente lingüísticos são relevantes, porém bastante secundários no cômputo geral" (Thomason \& Kaufman 1986: 35). Alhures, na mesma obra, os autores afirmam que "a mudança lingüística é um fato social com implicações lingüísticas” (p. 212).

A visão de formação da gramática crioula aqui defendida já fora antecipada pela escola dialetológica chamada "Wörter und Sachen" (palavras e coisas), à qual pertencia o fundador da crioulística Hugo Schuchardt. Ela defendia a tese de que a lingüística histórica deve levar em conta tanto a história interna quanto a história externa das palavras. Isso implica uma concepção segundo a qual a língua é antes de tudo um meio que permite a comunicação entre membros de uma sociedade. Assim sendo, é necessário partir de dois pressu-postos. O primeiro é o conhecido esquema da comunicação, repro-duzido na fig. 1. De acordo com ele, para que uma mensagem (M) enviada por um emissor (E) a um receptor (R) seja entendida é neces-sário que ambos compartilhem o mesmo código ou linguagem (L). 


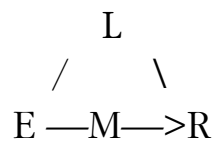

Figura 1

O segundo pressuposto decorre do primeiro. Para que o processo representado na fig. 1 seja viabilizado é necessário que E e $\mathrm{R}$ pertençam à mesma sociedade ou comunidade. Por isso, é preciso explicitar que comunidade só existe se há um povo (P), vivendo em determinado território (T), unificado por uma linguagem (L) própria. É o que se vê na fig. 2. Isso representa uma visão sincrônica de comunidade. No caso das comunidades e línguas crioulas - e no das não-crioulas também - esse quadro sincrônico é produto de uma construção histórica, resultante de diversas interações comunicativas entre membros da comunidade. Saussure diz que a fala vem sempre antes e que, "historicamente, a língua é produto da fala" (Saussure 1973: 27).

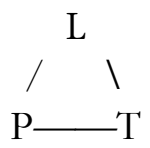

Figura 2

É importante ressaltar que o que entra em contato diretamente não são línguas (L), mas os povos (P) que as falam. As línguas os acompanham. Do ponto de vista histórico, as comunidades e as línguas crioulas resultaram do contato de um povo dominante e/ou colonizador, e respectiva língua $\left\{\mathrm{PL}_{1}\right\}$, com povos dominados e/ou colonizados, e respectivas línguas $\left\{\mathrm{PL}_{2}, \mathrm{PL}_{3}, \ldots, \mathrm{PL}_{\mathrm{n}}\right\}$, em determinado espaço ou território. A língua do povo dominante $\left(\mathrm{L}_{1}\right)$ é chamada em crioulística de língua lexificadora ou de superstrato. As línguas dos povos dominados $\left(\mathrm{L}_{2}, \mathrm{~L}_{3}, \ldots, \mathrm{L}_{\mathrm{n}}\right)$ são chamadas de línguas de substrato. 
Como se pode ver na fórmula que as representa, as línguas de substrato podem ser duas, três ou mais, dependendo da situação histórica concreta que se considere. A língua de superstrato geralmente é uma só, embora não se possa excluir a priori a possibilidade de intervenção de mais de uma.

O contato de $\left\{\mathrm{PL}_{1}\right\} \operatorname{com}\left\{\mathrm{PL}_{2}, \mathrm{PL}_{3}, \ldots, \mathrm{PL}_{\mathrm{n}}\right\}$ tem que acontecer em determinado espaço ou território (T). Observando os esquemas da figura 3, verifica-se que a primeira possibilidade de encontro entre um povo dominante e sua língua $\left\{\mathrm{PL}_{1}\right\}$ e povos dominados e suas línguas $\left\{\mathrm{PL}_{2}, \mathrm{PL}_{3}, \ldots, \mathrm{PL}_{\mathrm{n}}\right\}$ é, teoricamente, no território do povo dominante. É o caso de povos que imigram para o território de um outro povo, embora raramente esse contato resulte em uma língua crioula. Uma segunda possibilidade é o encontro se dar no território do povo dominado, ou no de um deles. Os exemplos mais conhecidos são os chamados crioulos de fortalezas - o crioulo português da Guiné-Bissau é um deles. A terceira possibilidade é a ideal; tratase do caso em que o contato do povo dominante com os povos dominados se dá em um terceiro território, que não é do primeiro nem dos segundos. Os casos mais conhecidos são os dos chamados crioulos de plantação, os "plantation creoles" de Bickerton (1988). Na fig. 3 temos as três possibilidades representadas graficamente.

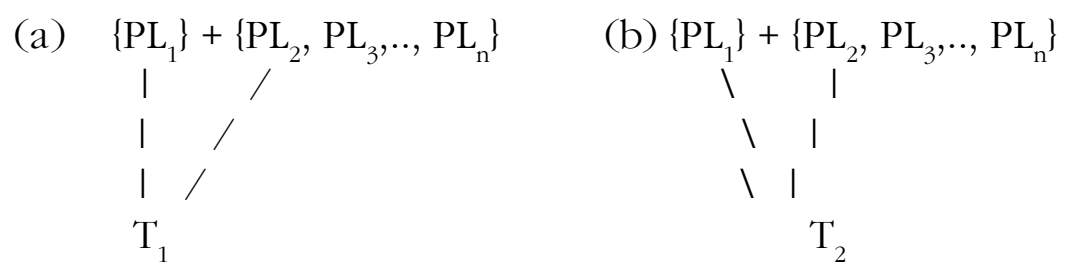

(c) $\left\{\mathrm{PL}_{1}\right\}+\left\{\mathrm{PL}_{2}, \mathrm{PL}_{3}, . ., \mathrm{PL}_{\mathrm{n}}\right\}$

Figura 3 
Uma quarta alternativa seria o encontro entre membros de $\left\{\mathrm{PL}_{1}\right\}$ com membros de $\left\{\mathrm{PL}_{2}, \mathrm{PL}_{3}, \ldots, \mathrm{PL}_{\mathrm{n}}\right\}$ se dar tanto em $\mathrm{T}_{1}$ quanto em $\mathrm{T}_{2}$. Isso poderia acontecer no caso de ambos habitarem territórios contíguos ou muito próximos um do outro. Trata-se da situacão ideal para o surgimento de um pidgin, que é por definição uma língua de contato entre povos falantes de línguas mutuamente ininteligíveis.

\section{O CICLO VITAL}

Os esquemas da Fig. 3 podem dar a entender que o processo histórico de formação da gramática crioula, vale dizer, de surgimento de uma língua crioula, é simples e direto. Na verdade, o modelo por assim dizer "clássico" para explicar esse processo, chamado de ciclo vital (Hall 1962, 1966), é bastante complexo. Para entendê-lo, vejamos uma das conceituações mais conhecidas de crioulo. Segundo Derek Bickerton, "um crioulo surge quando crianças adquirem um pidgin como sua língua nativa". O pidgin, por seu turno, "é uma língua auxiliar que surge quando falantes de diversas línguas mutuamente ininteligíveis entram em contato estreito" (Bickerton 1984: 173). Esse modelo é geralmente atribuído a Hall (1962). Na fig. 4 temo-lo representado esquematicamente.

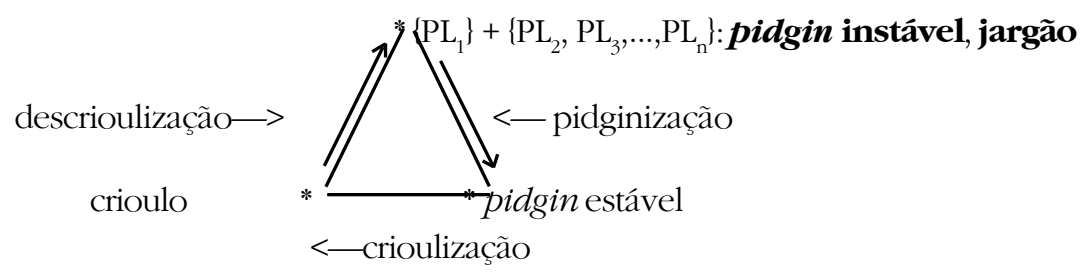

Figura 4

Partindo da fig. 4 podemos verificar as implicações dos conceitos tradicionais de "crioulo" e "pidgin". Como está implícito nas definições de Bickerton vistas acima (cf. também Bickerton 1981), um pidgin surge quando $\left\{\mathrm{PL}_{1}\right\}$ entra em contato estreito com $\left\{\mathrm{PL}_{2}, \mathrm{PL}_{3}, \ldots\right.$, 
$\mathrm{PL}_{\mathrm{n}}$ \}. Pelo "estreito" parece que Bickerton está sugerindo "em um mesmo território". Nas fases iniciais do contato tem-se um pidgin instável, ou jargão, ainda sem uma gramática própria independente da gramática da língua lexificadora e das gramáticas das línguas de substrato. Um exemplo de jargão ou pidgin instável poderia ser o russenorsk, (Broch 1927). Nesse estágio, a interação se dá apenas pelo modo pragmático. O modo sintático (Givón 1979: 2-7-233), intervém apenas quando o pidgin instável inicial se estabiliza (pidgin estável). Nesse momento, não se trata mais de um mero jargão, mas de uma língua propriamente dita, com uma gramática própria, como parece ser o caso do jargão chinook, apesar de ter "jargão" no nome (cf. Mühlhäusler 1986: 4-11, 134-176).

De acordo com esse modelo, o crioulo surge quando o pidgin estável é adquirido como língua materna por crianças da comuni-dade emergente. Portanto, por definição, crioulo é um ex-pidgin, ou melhor, pidgin nativizado (na seção 6, abaixo, voltarei ao conceito de nativização). Por fim, após formado (e até mesmo durante o processo de formação), o crioulo começa a se reaproximar da língua lexificadora ou de substrato, processo conhecido como de descriou-lização. Um bom exemplo de crioulo em fase adiantada de descriou-lização é o jamaicano.

Os seguidores do modelo do ciclo vital admitem outras possibilidades de evolução, além das mostradas na fig. 4. A primeira delas, a preferida por Bickerton, é a de o crioulo se formar dire-tamente a partir do jargão inicial, sem o intermediário do pidgin estável, como presumivelmente teria ocorrido com o havaiano, o saramaca, o sãotomense e outros crioulos "radicais". Afora isso, pode ocorrer também de o crioulo, após formado, se repidginizar, ou seja, voltar a ter a função de língua de contato, típica do pidgin. É o que ocorreu com o tokpisin nas "Highlands" da Papua Nova Guiné. Pode acontecer também de determinado crioulo que está sofrendo um intenso processo de descrioulização se recrioulizar. Isso se dá com os falantes do jamaicano em Londres e, provavelmente, com os falantes do crioulo caboverdiano em Lisboa. Para marcar sua identidade, eles super- 
enfatizam formas basiletais (nucleares, "puras"), mais até do que os compatriotas que não emigraram. Por fim, um crioulo - ou um pidgin estável - pode se rejargonizar, ou seja, sofrer um processo de deterioração das estruturas gramaticais, pelo fato de a língua voltar a ser mera língua de contato e, portanto, a constituir-se de meras estratégias individuais de comunicação, sem uma gramática própria. Para uma discussão detalhada desse assunto, pode-se consultar Couto (1990: 15-31).

\section{PROBLEMAS COM O MODELO DO CICLO VITAL}

Em seus escritos iniciais (1974), Bickerton admitia que a nativização (aquisição do pidgin como língua nativa por crianças) podia se dar tanto a partir do jargão inicial quanto a partir do pidgin estável. Em publicações posteriores (1980, 1984), ele passou a enfatizar apenas a primeira possibilidade.

O caso de crioulização a partir de um pidgin estável mais conhecido é o do tokpisin, crioulo inglês da Papua Nova Guiné. Os problemas começam a surgir quando autores como o já mencionado Mühlhäusler admitem que o tokpisin teria se expandido ainda como pidgin, ou seja, antes de adquirir falantes nativos, ou seja, nos termos do modelo "clássico" de crioulização, antes de se crioulizar (Mühlhäusler 1986: 176-205).

Afinal, será que tanto faz um crioulo se formar a partir do pidgin instável (jargão) inicial quanto a partir do pidgin estável? Será que é correto considerar o tokpisin em seu estágio estabilizado, e até mesmo expandido, como pidgin? Nesse caso o termo "pidgin" designaria coisas inteiramente diferentes uma da outra. Empirica-mente sabemos que o russenorsk, nome que se dá ao meio de comu-nicação que teria surgido do contato entre pescadores noruegueses e russos ao norte da Noruega, não tem uma gramática própria (cf. Broch 1927). Portanto, não pode ser chamado de língua. No entanto, a tradição crioulística e pidginística o tem considerado como um pidgin. Sendo ele tão diferente do tok pisin, que tem uma gramática estabilizada e até 
expandida, não pode ser classificado na mesma categoria que ele. A própria língua franca, que serviu como meio de contato entre espanhóis, franceses e italianos com falantes de dialetos árabes do norte da África, em torno do Mediterrâneo, desde a Idade Média até pelo menos o século XVIII, tem sido chamada de pidgin (Cifoletti 1989, Holm 1989: 606-609). No entanto, tampouco ela parece ter estruturas gramaticais independentes das estruturas das línguas que intervieram em sua formação (Schuchardt 1909).

Há outros problemas com o modelo em tela. Um dos mais importantes entre eles é a questão da nativização. Se considerarmos que para se transformar em um crioulo o pidgin deve tornar-se língua materna, pode-se perguntar: de quantas crianças? Para Bickerton (1991:37-38) basta uma. Porém, a maioria dos crioulistas não aceita essa idéia. Afinal, se apenas uma criança formasse uma língua, com quem ela interagiria (se comunicaria)? Como sabemos, toda criança aprende a falar na interação com os adultos que con-vivem com ela. Até hoje não se registrou nenhum caso desses. Portanto, até prova em contrário, a hipótese nativização deve ser descartada.

\section{A PROPOSTA DE JAKOBSON}

O processo de formação da gramática crioula apresentado na fig. 4 foi chamado de crioulização, e o de sua transformação foi chamado de descrioulização. De uma perspectiva mais geral, poderíamos chamar o primeiro de gramatizalização e o segundo de regramaticalização (usando esses termos em um sentido diferente do que lhes atribuem os estudiosos de "gramaticalização"), uma vez que se trata de uma revisão da gramática crioula por influência da língua dominante. Porém, só se pode falar em gramaticalização, aqui no sentido de nascimento de uma gramática, se ela inexistia antes, se havia um estado de agramaticalidade ou desgramaticalização anterior.

Pode-se dizer que, na verdade, o novo modelo consta das etapas desgramaticalização, gramaticalização e regramaticalização. A desgramaticalização se dá nos momentos iniciais do encontro de $\left\{\mathrm{PL}_{1}\right\}$ 
$\operatorname{com}\left\{\mathrm{PL}_{2}, \mathrm{PL}_{3}, \ldots, \mathrm{PL}_{\mathrm{n}}\right\}$, em que se verifica um desmoronamento das estruturas gramaticais de todas as línguas intervenientes. É justamente por isso que a comunidade emergente tem que criar (cf. Baker 1990) um meio de comunicação interétnica (MCI), até aqui chamado de pidgin, que poderá se desenvolver em um crioulo. Esse é o momento da gramaticalização, ou seja, de formação da gramática crioula, a partir dos escombros das gramáticas das línguas que entraram em contato. Depois de formada, a força centrípeta da língua dominante provoca um rearranjo na gramática crioula (descrioulização), que é justamente a regramaticalização.

Interpretar o processo de formação e transformação da gramática crioula como o ciclo desgramaticalização > gramatica-lização > regramaticalização pode dar a entender que se trata de algo novo. Na verdade, ele foi previsto independentemente por Roman Jakobson, ao falar da fonologia histórica, no início da década de 30, sob a forma do ciclo desfonologização > fonologização > refonolo-gização, nessa ordem (Jakobson 1970, 1978). A desfonologização é definida por Jakobson do seguinte modo: "A e B se opõem fonolo-gicamente, ao passo que entre $\mathrm{A}_{1}$ e $\mathrm{B}_{1}$ não há nenhuma diferença fonológica”. Tratase, assim, de uma "desvalorização fonológica" (Jakobson 1970: 319). Ele aduz vários exemplos das línguas eslavas. Llorach (1967:132-133) mostra que no castelhano e no catalão medievais /b/ e /v/ eram fonemas distintos. Porém, quando $/ \mathrm{v} /$ passou a ser pronunciado como [ $\beta]$ confundiu-se com o $/ \mathrm{b} /$ intervo-cálico, que também era [ $\beta]$. Com isso, a relação original $/ \mathrm{b} /-/ \mathrm{v} /$ se transformou na relação $/ \mathrm{b} /-/ \beta /$. No galego-português, a distinção fonológica existente entre /ts/ (cem) e /s/ (sem) se desfez, dando lugar a um único fonema $/ \mathrm{s} /$. O mesmo se deu com /dz/-/z/ (cozer, coser) que confluíram em /z/, com /t $\mathrm{f} /-/ \mathrm{s} /$ (chaga, leixar) que viraram $/ \mathrm{s} / \mathrm{e} \mathrm{com} / \mathrm{d}_{3} /-/ 3 /$ que se neutralizaram em /3/ (Teyssier 1987 26-27).

Quanto à fonologização, Jakobson afirma que "entre A e B não há nenhuma diferença fonológica, enquanto que entre $\mathrm{A}_{1}$ e $\mathrm{B}_{1}$ essa diferença existe" (Jakobson 1970: 321). Trata-se, portanto, do surgimento de uma distinção fonológica onde ela não existia. Os 
exemplos do autor consistem basicamente de variantes combina-tórias de fonemas que passam a ser dois fonemas distintos. Assim, no polábio antigo, o fonema $/ \mathrm{x} /$ era realizado como a espirante velar surda $[\mathrm{x}]$ antes de algumas vogais; antes de outras vogais, ocorria como espirante palatal surda [ç], de modo que eram apenas variantes combinatórias de um único fonema. Tornaram-se dois fonemas autônomos quando as vogais fracas médias e baixas se coalesceram, com o que se deu uma diferenciação em palavras como [sauxxa] (feminino) e [sauça] (neutro), de modo que o par /x-ç/ passou a ser uma oposição fonológica (Jakobson 1970: 322).

A adoção de empréstimos é outra fonte de fonologizações. Em russo, [f] só ocorria em final de palavras como variante ensurdecida de /v/, como no nome próprio Gorbatchof. Devido à importação de termos que continham [f] em outras posições, essa variante se fonologizou, formando a correlação /v/-/f/. Em português, o som [t]] é apenas um alofone de [t] antes de [i], em alguns dialetos. No entanto, em itens lexicais periféricos como tchau, tchan, tchê, tchaco, Tcheco e Tchetchênia, ele já está ocorrendo em outros contextos fonéticos. Em expressões de gíria ele já apareceu em mintchura, tchurma e pitchula, entre outros. Em alguns dialetos do nordeste, ele ocorre como alofone de /t/ se vier precedido de [i] ou [y], como em [direyt fu] (direito). Por fim, no Mato Grosso ele substitui o fonema $/ \mathrm{J} /$, de modo que uma frase como O Coxipó (rio) enche e o peixe se vai é pronunciada por

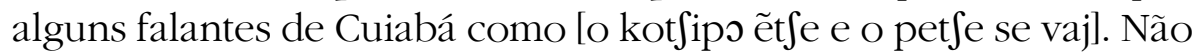
se deve desprezar nem mesmo a influência do espanhol dos países que nos circundam. Pois bem, devido a tudo isso parece que o par [t]-[t $\left.\int\right]$ tende a passar por um processo de fonologização, resultando na distinção fonológica /t/-t $\int /$, como no espanhol.

A refonologização, por fim, consiste em uma reorganização de oposições fonológicas. Segundo Llorach (1967: 133), "não se criam nem se perdem distinções fonemáticas; o que ocorre é uma reorganização da estrutura do sistema”. Assim, quando a consoante vibrante múltipla alveolar do português /r/ de carro e r $u a$ passou a realizar-se como vibrante múltipla uvular $[R]$ e, por fim, como fricativa 
velar [x], deixou a oposição isolada em que se inseria (as líquidas) para fazer parte da oposição velar oclusiva $/ \mathrm{k}, \mathrm{g} / \mathrm{e}$ fricativa $/ \mathrm{x} /$.

Em síntese, a desfononologização é a desgramaticalização fonológica, a fonologização a gramaticalização fonológica e a refononologização a regramaticalização fonológica. De acordo com minha proposta, a gramaticalização (precedida da desgramaticalização) equivale à crioulização, e a regramaticalização à descrioulização.

\section{CRIOULIZAÇÃO SEM PIDGINIZAÇÃO}

Para a discussão do novo modelo, partamos do esquema da fig 5. Como o conceito de descrioulização é polêmico, talvez fosse melhor substituí-lo por transformação da gramática, com a conse-qüente substiuição de crioulização por formação da gramática. De qualquer forma, isso não interfere na argumentação que segue.

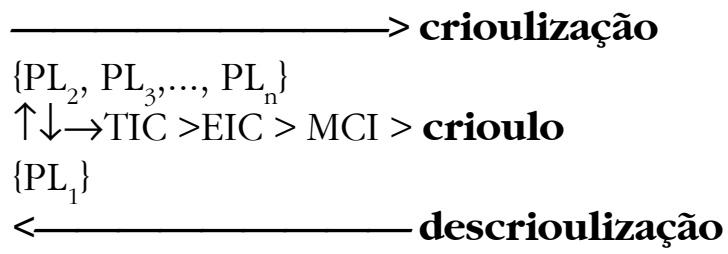

(as setas verticais indicam interação; a seta horizontal indica seu resultado)

Figura 5

Voltemos à situação de contato de representantes de diversos povos e respectivas línguas mutuamente ininteligíveis em determinado território. Como o esquema mostra, o que entra em contato em geral é um povo dominante e sua língua $\left\{\mathrm{PL}_{1}\right\}$ com dois ou mais povos dominados e suas línguas $\left\{\mathrm{PL}_{2}, \mathrm{PL}_{3}, \ldots . . \mathrm{PL}_{\mathrm{n}}\right\}$. Na ausência de um meio de comunicação, os indivíduos não têm outra alternativa que fazer tentativas individuais de comunicação (TIC). Em geral são 
membros do povo dominante que primeiro se dirigem a membros do(s) povo(s) dominado(s), fato indicado pela seta ascendente inicial (à esquerda), e como se pode deduzir dos exemplos da Carta de Caminha de (3)-(5). Por serem individuais, as TIC podem ser como a do exemplo de (1), dito por um brasileiro monolíngüe na Alema-nha, a quem uma auto-locadora queria entregar um carro diferente do que encomendara.

\section{(1) I paguei, I faço questão de my car}

Outra possibilidade é (2), dito por brasileira semi-analfabeta na Europa, para pedir comida.

(2) $[\mathrm{m} \Lambda \mathrm{m}, \mathrm{m} \Lambda \mathrm{m}, \mathrm{m} \Lambda \mathrm{m}]$, com a mão direita apontando para a boca

Enfim, os recursos de que se pode lançar mão são inteiramente imprevisíveis, incluindo gestos, recursos paralingüísticos e assim por diante. No que tange à mímica, a Carta de Caminha nos dá os exemplos de (3)-(5), entre outros.

(3) “...Nicolao Coelho lhes fez sinal que posessem os arcos, e eles o poseram" (Carta, p. 85)

(4) “... um deles pôs olho no colar do capitão e começou d'acenar com a mão pera a terra e depois pera o colar como que nos dezia que havia ouro..." (p. 89)

(5) "Mostraram-lhes um papagaio pardo que aqui o capitão traz, tomaram-no logo na mão e acenaram logo pera a terra como que os havia i" (p. 89).

Do que se deu ulteriormente, não temos conhecimento.

Se o contato entre os dois povos continuar, alguns itens lexicais tenderão a ser de domínio comum, e algumas TIC que se mostrarem comunicativamente eficazes poderão se cristalizar em alguns indivíduos como estratégias individuais de comunicação (EIC). No momento, não tenho exemplos portugueses. No entanto, é fácil imaginar que as TIC que começassem a ser repetidas por alguns 
indivíduos, numa espécie de clichê, se transformariam em EIC. Exemplos como os de (6)-(8) de Bickerton podem ser considerados como EIC (os dois últimos de Bickerton 1981:11).

(6) as bihoa stei taim 'when we used to stay here'

(7) da pua pipl awl poteito it 'the poor people ate only potatoes'

(8) wok had dis pipl 'this people work hard'

Como se vê nesses exemplos, os itens lexicais são todos ingleses. Quanto à gramática, o pouco que se pode identificar é japonês em (6)-(7) e filipino em (8). Portanto, é de se presumir que esse primeiro passo de gramaticalização comece justamente com itens gramaticais esparsos tirados das línguas dos povos dominados.

As EIC, apesar de já serem repetíveis e repetidas, são ainda individuais. No entanto, como se cristalizaram por terem se mostrado eficazes, de certa forma sua existência implica o ouvinte, isto é, já implicam certo grau de socialização. Mantendo-se o contato por mais tempo, o conjunto de EIC que se mostrar eficaz tenderá a se generalizar entre os membros da comunidade emergente e se cristalizar em um meio de comunicação interétnica, ou interlin-güística (MCI). Esse MCI é o início do processo de formação da gramática crioula.

De meu conhecimento, foi o não crioulista William S. Y. Wang quem fez uma das primeiras referências à transição de itens lexicais soltos para construções frasais em uma situação de contato de línguas mutuamente ininteligíveis. De acordo com ele, "quando as necessidades comunicativas vão além do nível lexical, as palavras se juntam em estruturas hierárquicas, que no final serão linearizadas" (Wang 1984: 210). De acordo com Bickerton, as funções sintáticas são indicadas apenas pela ordem, sendo SVO a ordem não-marcada ("universal"). Isso ocorre com a fixação de uma vida comunitária multiétnica no território comum. Nesse momento, tem-se o crioulo.

Como se vê, o crioulo é uma língua mista, freqüentemente com a maioria do léxico proveniente da língua dominante (político, militar e economicamente) e a gramática proveniente em grande parte das línguas inferiorizadas político, militar e sócio-economicamente. Uma 
parte dessa gramática se deve também a tendências gerais, abreviadas como TGA mais abaixo. Em suma, na formação da gramática das línguas crioulas temos influência tanto do substrato, das línguas dominadas, quanto da gramática universal, sem excluir a possibilidade de influência da língua dominante. O fato é que as línguas crioulas em geral têm um sistema gramatical com forte tendência a estruturas não-marcadas.

No entanto, o prestígio e o poder da língua dominante continua se insinuando, de modo que até mesmo antes de se completar a formação de sua gramática (seta da crioulização), a língua crioula passa por um processo centrífugo na direção oposta à que lhe deu origem, ou seja, o processo de descrioulização. Isso faz com que as comunidades crioulófonas estejam sempre em um equilíbrio instável, apresentando sempre um continuum que vai desde uma variedade basiletal até uma variedade mais próxima do superstrato, ou seja, uma variedade acroletal. No meio de ambas, existe uma variedade constituída pelo que se chama de mesoleto.

É por esses e outros motivos que a situação lingüística nas comunidades crioulófonas como um todo sempre se apresenta complexa, desafiando os modelos descritivos existentes e levando os especialistas a se perguntarem se se trata apenas de um sistema que vai desde o basileto até o acroleto, passando pelo mesoleto, ou de sistemas co-existentes. Neste último caso, o basileto seria um sistema, o mesoleto seria outro e o acroleto um terceiro sistema e assim por diante. Quando se diz que o crioulo tem uma gramática simples, não marcada, não se trata de uma contradição. Nese caso, pensa-se sobretudo no basileto, ou seja, a variedade do crioulo tida como "pura".

\section{COMUNITARIZAÇÃO}

A tese que defendo, e que deixo aqui como hipótese para ser ratificada ou retificada com novos dados empíricos, é a de que assim que o agrupamento formado por $\left\{\mathrm{PL}_{1}\right\}+\left\{\mathrm{PL}_{2}, \mathrm{PL}_{3} \ldots \mathrm{PL}_{\mathrm{n}}\right\}$ ou apenas por $\left\{\mathrm{PL}_{2}, \mathrm{PL}_{3} \ldots \mathrm{PL}_{\mathrm{n}}\right\}$ se consolida, consolida-se também um MCI. Com ele, 
começa a cristalizar-se também uma comunidade, com uma L própria, diferente de todas as línguas contactantes. Por outras palavras, diferente de todas as línguas dos povos que intevieram em sua formação. Portanto, podemos dizer que o crioulo surge assim que o MCI passa a ser a língua principal de uma comunidade. A partir desse momento, a noção de nativização, que é parte integrante da definição de crioulo vista acima, se torna desnecessária. Com efeito, já vimos acima que esse conceito é problemático, mesmo que distingamos nativização coletiva e nativização individual, como faz (Gilbert 1986: 17).

Quanto ao pidgin, pode-se dizer que o importante na formação de um crioulo não é propriamente o fato de um grupo de crianças (ou apenas uma, como pensa Bickerton) da comunidade adquirilo como língua nativa. Partindo dos pressupostos recém-vistos, o que marca a emergência de um crioulo é o fato de o MCI se comuni-tarizar, ou seja, transformar-se na língua principal da comunidade formada por $\left\{\mathrm{PL}_{1}\right\}+\left\{\mathrm{PL}_{2}, \mathrm{PL}_{3} \ldots \mathrm{PL}_{\mathrm{n}}\right\}$ ou apenas por $\left\{\mathrm{PL}_{2}, \mathrm{PL}_{3} \ldots \mathrm{PL}_{\mathrm{n}}\right\}$ influenciado por $\left\{\mathrm{PL}_{1}\right\}$.

Se alguém quiser chamar o MCI de pidgin, com o mesmo sentido, não faz mal. Só que não poderia falar em "pidgins estáveis" nem em "pidgins expandidos", uma vez que o MCI é apenas o que alguns autores chamam de jargão inicial. Pode até ser que haja pidgins (ou MCI) estabilizados mas só com a função de língua franca entre povos aloglotas que vivam em territórios contíguos, como vimos na quarta possibilidade de contato na fig. 3 acima. No momento em que esse "pidgin" passar a ser a língua principal de uma determinada comunidade, deixará de ser pidgin, adquirindo as feições de crioulo. Em síntese, sempre que um "pidgin", isto é, um MCI, passar a ter um território próprio e fixo será um crioulo. De certo modo comunitarização é o mesmo que territorialização. Se alguém quiser continuar usando o conceito de "pidgin", terá que redefini-lo, a fim de não cair em contradições.

Em consonância com o que disseram Thomason \& Kaufman (1988) acima, as línguas crioulas não podem ser definidas apenas 
lingüisticamente. O movimento estrutural na direção de estruturas e fenômenos não-marcados é o resultado de situações de contato, ou seja, tem como causa fatos sócio-históricos. Esta é mais uma forte razão para se preferir comunitarização a nativização.

A concepção de crioulo como um MCI comunitarizado não é nova. Já na década de 30 Leonard Bloomfield dizia que "quando o jargão se torna a única língua do grupo dominado, ele é uma língua crioulizada" (Bloomfield 1933: 474). Como se vê, o autor chama o MCI de "jargão" e o crioulo de "língua crioulizada". O importante é que ele deixa bem claro que um crioulo surge quando um meio precário de comunicação interétnica, formado de línguas que entram em contato estreito, passa a ser a língua principal da comunidade mista emergente.

Na década de 70 Albert Valdman opunha à "nativização, definida como estabilização, expansão e complexificação de um pidgin quando ele é adquirido como língua primeira, a elaboração, ou seja, quando esses processos são adquiridos como língua segunda por adultos" (Valdman 1977: 108). Isso porque "a elaboração e a nativização não diferem no plano cognitivo” (p. 136). Como se vê, para Valdman o próprio conceito de pidgin é dispensável.

Salikoko Mufwene também toca na questão, embora não a desenvolva. Ele afirma que "a concepção de 'crioulo' que não pressupõe a nativização é mais operacional”. Logo abaixo afirma que

"o critério da vernacularização proposto por Valdman, assimilável à função como língua principal ('primary language' em inglês) proposta por Mühlhäusler, parece mais adequada para distinguir os crioulos dos pidgins" (Mufwene 1989: 75).

Vê-se que o autor emprega o conceito de "pidgin", o que, mais uma vez, reforça minha tese de que ele pode ser usado, embora não seja indispensável. Sua concepção não ficaria em nada alterada se, no lugar de "pidgin" empregássemos o termo "MCI". E isso não seria apenas troca de rótulos (cf. Baker 1990).

Para confirmar a desnecessidade do conceito de pidgin, sobretudo de "pidgin estabilizado" e de "pidgin expandido", como 
propõem Todd (1990) e Mühlhäusler (1986), é importante reiterar que, do ponto de vista estrutural, não há nenhuma diferença fundamental entre aquilo que foi chamado por tais nomes e os crioulos. O próprio Mühlhäusler reconhece isso. Porém, muito antes dele Reinecke já dizia que "no que concerne à estrutura, provavel-mente não se encontrará nenhuma diferença significativa entre as três classes de línguas marginais aqui discutidas" (Reinecke 1937: 141). As três classes de línguas marginais a que ele alude são os crioulos de plantação (plantation creole dialects), os crioulos de fortalezas (settler's creole dialects) e os pidgins (trade jargons).

Por fim, temos o testemunho de Morris Goodman. Para ele, "há evidência de que a nativização não altera necessariamente a estrutura de um pidgin" (Goodman 1984: 194). O exemplo que ele aduz é o do kinubi, que seria a nativização do pidgin árabe de Juba. Eles são muito semelhantes estruturalmente. A nativização não alterou substancialmente as estruturas do pidgin inicial. O próprio Mühlhäusler (1986: 204) afirma isso.

Resumindo, eu salientaria que o crioulo surge quando surge uma nova comunidade formada de povos aloglotas que convergiram em um mesmo espaço e cujos membros precisaram comunicar-se uns com os outros. Nos estágios iniciais desse contato, ainda não há um instrumento de intercomunicação, o que faz com que o pouco de entendimento que se dá é apenas uma comunicação pragmática. À medida que a convivência entre esses povos vai se intensificando, vai surgindo um MCI que, assim que se cristaliza, é um crioulo. Logo, os conceitos chaves na crioulização são os de territorialização, ou seja, de fixação de uma comunidade em determinado território, e o de comunitarização de um MCI, ou seja, o momento em que ele se transforma na língua principal (primary language) da comunidade em questão.

Adaptando uma proposta de Lebel (1981, 1996), podemos distinguir os níveis de comunicação primário, essencial e ótimo. Um bom exemplo de interação comunicativa primária, é a que se deu entre os membros da esquadra de Cabral e os índios tupinambás de Porto Seguro, em 1.500. Trata-se de uma interação comunicativa em que 
não há nenhum código comum. Do ponto de vista lingüístico, e ignorando a língua tupi dos índios e o português dos europeus, poderse-ia dizer que se estava em um nível zero de gramaticali-zação, ou de gramática zero (GØ), equivalente ao estado inicial ( $\left.\mathrm{E}_{0}\right)$ de Chomsky (1988), em que o que se tem é a gramática universal (GU). É o momento da desgramatizalização. Isso quer dizer que o mínimo de eficácia comunicativa que houver (se houver) se deverá não à existência de um código comum, ainda que tosco, mas à seme-lhança de condições biológicas de existência sobre a face da terra. Trata-se, portanto, de uma comunicação por assim dizer natural.

O nível essencial de interação é aquele em que já há o essencial de conhecimentos compartilhados, já existe pelo menos um mínimo de gramaticalização. No caso da crioulização, tratar-se-ia do início do surgimento de um meio de comunicação interétnica ou interlingüística. Esse nível de gramática essencial (GE) equivale ao estado estável $\left(\mathrm{E}_{\mathrm{e}}\right)$ de gramaticalização de Chomsky.

Mas, o ser humano tem necessidades que vão muito além do mínimo essencial expressiva e comunicativamente. Quando esse mínimo é atingido, e as necessidades básicas são atendidas, ele sente necessidade de atingir o belo, o lazer, o prazer, enfim, de usar a língua ludicamente. Ele sente necessidade de atingir um nível ótimo de comunicação e expressão do pensamento. O nível ótimo de comunicação só é atingido quando se chega ao estágio de gramatica-lização máxima, ou seja, quando a língua incorpora a periferia marcada $\left(\mathrm{P}_{\mathrm{m}}\right)$. Trata-se da etapa final de gramaticalização, ou de formação da gramática crioula. Essa etapa coincide com a de consolidação da nova comunidade. Como diz Saussure (1973: 21), só na sociedade como um todo temos a gramática completa, que pode ser chamada de gramática da comunidade (GC). Essas equivalências estão mostradas na fig. 6. 
Nivel de comunicação

1. primário

2. essencial

3. ótimo

\section{Estágio de gramaticalização}

1. GØ; $\mathrm{E}_{\mathrm{o}} ; \mathrm{GU}$; desgramatizalização

2. GE; $\mathrm{E}_{\mathrm{e}}$; gramaticalização

3. GC; $\mathrm{P}_{\mathrm{m}}$; gramaticalização $\mathrm{O}_{2}$

Figura 6

\section{TGA}

A abreviatura TGA está por "țendências gerais de apropriação, approximação, a comodação ou a dequação lingüística ao ouvinte, que se dão em situações de contato. Por "appropriação", deve-se entender tanto a a quisição de L1 pela criança quanto a a aprendizagem de L2, em geral por adultos. A a acomodação (cf. Thomason \& Kaufman 1986) inclui o "foreigner talk" e o "baby talk". "Foreigner talk" consiste nas "simplificações" que um falante faz em sua língua na presunção de ser entendido pelo ouvinte aloglota (Ferguson 1971). Quanto a "baby talk", trata-se da linguagem que o adulto usa para com crianças pequenas, imitando o que a criança presumivelmente diria (Ferguson \& DeBose 1971). O "a" pode referir-se também aos fenômenos de mudança ou alteração lingüística que se dão na evolução histórica e na variação sincrônica.

Resumindo, temos, em primeiro lugar, contato da criança com a língua do adulto, na aquisição de L1. Nas fases iniciais, ela ainda não dispõe de um sistema lingüístico próprio, mas apenas do dom biológico para a língua. Por isso, o contato é, digamos, da GU com a língua da comunidade a que ela pertence. Em segundo lugar, temos o contato da língua materna do aprendiz (em geral adulto) com a língua que está aprendendo, ou seja, L2. Em terceiro lugar, contato de falante de L1 com não-falantes de L1, ou seja, a tentativa por parte do falante de "simplificar" sua fala com ou intuito de ser entendido, ou seja, de se acomodar à língua do ouvinte aloglota. Em quarto lugar, temos as mudanças ou alterações que se dão na língua pelo contato de dialetos. 
Os tipos de contato vistos até aqui são todos interlingüísticos, ao passo que este é intralingüístico. Trata-se, portanto, da variação sincrônica. Por fim, pode acontecer de ocorrerem mudanças devido à ausência de contato. Isso se dá quando há isolamento de um dialeto ou variedade lingüística em áreas geográficas distantes. Mas, nesse caso, não se trataria de contato desse dialeto isolado com outras realidades lingüísticas? O importante é que toda e qualquer mudança ou alteração lingüística se deve ao contato, direta ou indiretamente ou até mesmo a ausência do contato, que Chaudenson chama de "ausência de pressão normativa" (Chaudenson 1989).

Na verdade, o conceito de TGA já foi avançado por diversos autores. Thomason \& Kaufman (1986), por exemplo, falam em TGA sob o nome de "universal structural tendencies" (tendências estruturais universais), enquanto que Ferguson (1971) fala em "universal simplification process" (processo universal de simplificação). Portanto, não há nada de novo nesse conceito. O que estou tentando fazer é apenas retomá-lo, sistematizá-lo e mostrar que ele pode unificar fenômenos antes tidos como independentes, embora Jakobson (1970) já tenha tenha tentado fazê-lo.

A área de aquisição de L1 pela criança já está bastante desenvolvida. O que vou fazer aqui é apenas dar alguns exemplos, para que se vejam as semelhanças dos fenômenos que aí se dão com os da pidginização e da crioulização.

(1) (a) Cê qué mançana 'eu quero maçã'; (b) Aninha cabô 'não vejo mais a foto da Aninha'; (c) kafu mamãe 'carro da mamãe' (2 anos e 3 meses)

(2) (a) aba 'água', (b) xixi, (c) mãm 'mão', (d) mamã 'banana', (e) koka 'boca' (1 ano e 3 meses)

Para mais exemplos portugueses e discussão, pode-se consultar Martins (1977).

No exemplo sintático de (1) (a) vê-se que cê qué se cristalizou como uma expressão de volição, o que caracteriza uma EIC. Em (1c) tem-se o início da sintaxe, pois foi a primeira combinação de morfemas 
de Aninha. Nos exemplos fonológicos de (2), há uma série de simplificações. Em (2a) vemos a velar bilabializada $\left[\mathrm{g}^{\mathrm{w}}\right]$ que virou simplesmente [b]. Ou seja, a criança manteve os traços [sonoro] e [labiall, e suprimiu o traço mais marcado [dorsal]. O exemplo de (2c), apesar de ter uma consoante na coda silábica, também vai na direção do menos marcado. Na verdade, a coda é uma reduplicação do [m] do aclive silábico. Como sabemos, a reduplicação é um dos processos menos marcados na criatividade (gerativa) lingüística - ela é o início da morfologia. Além disso, com ela a criança evitou o ditongo português altamente marcado [ãw]. Reduplicação se dá também em (2d), em que o [b] de boca se assimila integralmente ao [k].

Para as TGA que se dão na aprendizagem de uma segunda língua (L2), não tenho muitos exemplos. Entretanto eles abundam na literatura pertinente. Em (3)-(6) pode-se ver alguns exemplos tirados de Schuman (1972: 150, 1978:357).

(3) We drive he father car 'nós dirigimos o carro do pai dele'

(4) (a) He play baseball everyday; (b) he play baseball yesterday; (c) he play baseball tomorrow; (d) he play baseball now/he playing baseball now

(5) (a) He open the door?; (b) where he put the book?; (c ) what she say?

(6) (a) I no see; (b) I no use television

Em (3) a forma reta do pronome be está funcionando como possessivo ( is ). Nos exemplos de (4) nota-se a ausência de flexão da terceira pessoa do singular (plays). O advérbio everyday de (4a) indica o aspecto habitual. O tempo também está expresso por advérbios: yesterday para passado (4b) e tomorrow para futuro (4c). Em (5) temos a interrogação sendo expressa apenas pela entoação, sem o morfema interrogativo inglês. Em (6), finalmente, temos a negação colocada antes do verbo.

Vejamos agora alguns exemplos de TGA no foreigner talk. Em uma pesquisa feita por alunos meus com 25 informantes obtivemos 
alguns resultados que corroboraram os de Ferguson (1975), que tomamos como modelo. Vejamos alguns deles.

(7) (a) você e ela irão; (b) ele se suicidou; (c) venha e fale comigo amanhã. Não esqueça!; (d) eu não falo sua língua. Você entende a minha?; (e) você é mais alto do que eu.

Para o exemplo de (7a), o verbo ocorreu não flexionado, sendo que alguns informantes usaram go por irão e outros simplesmente omitiram o verbo. Para a futuridade, ocorreu um advérbio de tempo com muita freqüência. No caso de (7b), a maioria dos informantes substituiu o verbo suicidar por matar, sendo que a idéia de reflexividade foi indicada por ele mesmo, ele e até se. Na produção de (7c), em geral evitaram-se os imperativos venha e fale, tendo aparecido o infinitivo. Quanto ao pronome, freqüentemente ocorreu como eu. Para (7d), também usaram-se infinitivos, sendo que um informante usou speak por falar. Por fim, a idéia de mais do que, foi expressa com freqüência por Eu pequeno/você grande, com a cópula omitida. Em Naro (1978) e Martins (1990) temos mais exemplos portugueses.

Passemos, finalmente, às TGA que ocorrem no baby talk.

(8) Pega bola dá papai (dito por um professor a sua filha de 2 anos) (9) (a) Cê qué eu vô?, (b) futa 'fruta', (c) patu 'prato', (d) pepeta 'chupeta'

No exemplo (8) temos o que em crioulística se chama de serialização verbal. De acordo com Bickerton (1981) isso se dá para indicar casos, suprir falta de preposições. Assim, o verbo dá de (8) indica a função de beneficiário da ação, de modo que a frase equivale a Pegue a bola para o papai, semelhante ao anobonês e fa da ine ('ele falar dar ele', isto é, 'ele falou para ele ${ }_{2}$, ele falou-lhe'). Em (9a) notase a ausência do pronome relativo; as duas orações foram simplesmente justapostas, sem as transformações exigidas pelo português padrão. Em (9b, c, d) ocorrem fenômenos já comentados acima, ou 
seja, simplificações silábicas na direção de CV e reduplicação (9d). Como o baby talk seria uma imitação do que os adultos acham que seria a linguagem infantil, todos os exemplos de aquisição de L1 vistos acima em princípio poderiam ocorrer aqui também (cf. Ferguson 1971, Stoel-Gammon 1976 e Martins 1977).

\section{CONCLUSÃO}

Algumas das implicações do novo modelo de crioulização já foram vistas acima. A primeira é que o conceito de pidgin é dispensável. A segunda é conseqüência lógica da dispensabilidade do pidgin. Não havendo nenhum pidgin prévio, tampouco haverá nativização, pois quando se fala nela quer-se dizer "nativização de um pidgin".

Uma outra implicação importante desta proposta é que nos fornece um arcabouço teórico que permite demonstrar que muita coisa que se tem chamado de "língua pidgin" não passaria de uma coleção de TGA aleatórias, irrepetidas e irrepetíveis. O "pidgin russenorsk", por exemplo, é bem provável que não passe de um conjunto de "enunciados" de pessoas (russos ou noruegueses) tentando falar uma língua desconhecida, e que casualmente alguém registrou. É como se registrássemos alguns "enunciados" de alemães tentando falar português, em épocas diferentes - um em Belém, outro em São Paulo, outro em Porto Alegre e assim por diante - e as considerássemos como "textos" de um "pidgin portalemão", com uma gramática independente da do português e da do alemão. Nesse caso, onde (em que comunidade) serie esse pidgin falado? Enfim, não temos nenhuma garantia de que aquilo que se chama "russenorsk" estivesse de algum modo gramaticalizado, a despeito de Slobin (1980: 62-66) e Jahr (1996). Em suma, como é que se pode dizer que se trata de uma língua (pidgin)? Por outras palavras, o pidgin é uma língua ou apenas o que se chama de jargão (concepção de Bickerton), ou seja, um pequeno vocabulário compartilhado usado sem sintaxe, ou com laivos da sintaxe de L1? 
O conceito de TGA tem uma vantagem adicional. Além de ser útil no estudo da crioulização, pois a enquadra em um contexto mais geral, mostra que fenômenos aparentemente disparatados pertencem à mesma classe. Para exemplificar a afinidade entre linguagem infantil e baby talk, eu lembraria o caso de um pai que disse a sua filha [futa], apontando para uma fruta, e ela repetiu [puta]. No primeiro momento temos um exemplo de TGA da linguagem infantil; no segundo temos uma TGA que surge na linguagem do adulto "simplificando" sua fala para presumivelmente se aproximar do que a criança diria ( "baby talk"). Por fim, O conceito de TGA nos livraria do beco-sem-saída dos chamados "universais da linguagem". Elas não são apriorísticas como os presumíveis universais.

Uma outra questão importante é o fato de o novo modelo ser mais simples do que o do ciclo vital. Em ciência, entre um modelo mais simples e um modelo mais complexo que dão conta dos mesmos fatos, deve-se dar preferência ao modelo mais simples.

\section{REFERÊNCIAS BIBLIOGRÁFICAS}

ARENDS, Jacques. Towards a gradualist model of creolization. In: Byrne, F. \& J. Holm (orgs.). Atlantic meets Pacific. Amsterdam: Benjamins: 371-380, 1993.

BAKER, Philip. Off target? Journal of pidgin and creole languages 5:1.107-119, 1990.

BICKERTON, Derek. Creolization, linguistic universals, natural semantax and the brain. In: Day, R. (org.) Issues in English creoles. Heidelberg: Julius Groos Verlag (original de 1974), 1980.

. Roots of language. Ann Arbor: Karoma, 1981.

. The language bioprogram hypothesis. The brain and behavioral sciences 7(2).173-221, 1984.

. Creole languages and the bioprogram. In: Newmeyer, F. J. (org.) The Cambridge Survey vol. II. Cambridge: Cambridge Press: 268-283, 1988.

. On the supposed "gradualness" of creole development. Journal of pidgin and creole languages 6(1).25-58, 1991.

BLOOMFIELD, Leonard. Language. Londres: Allen \& Unwin, 1933. 
BROCH, Olaf. Russenorsk. Archiv für Slavische Philologie 41. Band: 14-262, 1927. Carta de Pero Vaz de Caminha, A. Rio de Janeiro: Livraria Agir, 1965.

CHAUDENSON, Robert. Créoles et enseignement du français. Paris: L'Harmattan, 1989.

CHOMSKY, Noam. Language and problems of knowledge. The Managua lectures. Cambridge: The MIT Press, 1988.

CIFOLETTI, Guido. La lingua franca mediterranea. Pádua: Unipress, 1989.

COUTO, Hildo H. do. Introdução ao estudo das línguas crioulas e pidgins. Brasília: Editora da UnB, 1996.

FERGUSON, Ch. A. Absence of copula and the notion of simplicity. In: Hymes, D. (org.): 141-150, 1971.

\& Ch. E. DeBose. Simplified registers, broken language, and pidginization. In: Valdman, A. (org.). Pidgin and creole linguistics. Bloomington: Indiana University Press: 99-125, 1977.

GILBERT, Glenn. 1986. The language bioprogram hypothesis: Déjà vu? In: Muysken, P. \& N. Smith (orgs.) Substrata versus universals in creole genesis. Amsterdam: John Benjamins: 15-23.

GIVÓN, Talmy. On understanding grammar. N. York: Academic Press, 1979.

GOODMAN, Morris. Are creole structures innate? The behavioral and brain sciences 7(2).193-194, 1984.

HALL JR., Robert A. The life-cycle of pidgin languages. Lingua 11.151-156, 1962. . Pidgin and creole languages. Ithaca, N.Y.: Cornell University Press, 1966.

HOLM, John. Pidgins anc creoles 2 vols. Cambridge: Cambridge University Press, 1988/9.

HYMES, Dell. "Introduction” a Hymes (org.): 65-90, 1971a. . (org.) Pidginization and creolization of languages. Cambridge: Cambridge University Press, 1971b.

JAHR, Ernst Håkon. On the pidgin status of Russenorsk. In: Jahr, E. H. \& I. Broch (orgs.) Language contact in the Arctic. Berlim: Mouton de Gruyter: 107-122, 1996.

JAKOBSON, Roman. Principes de phonologie historique. In: Trubetzkoi, N. S. Principes de phonologie. Paris: Klincksieck: 315-336 (apêndice). Original de 1931 TCLP. Versão inglesa: "Principles of historical phonology". In: Baldi, P. \& N. Werth 1978. (eds.) Readings in historical phonology. Pennsylvania University Press: 103-120, 1970. 
LEBEL, Jean-Guy. La place de la correction phonétique dans l'approche communicative. In: Bulletin d'Information II,3.25-34, 1981.

. La place da la correction phonétique dans un cours de langue. In: Pesquisa lingüistica I.1-22 (UnB), 1996.

LLORACH, Emilio A. Fonología española. Madri: Editorial Gredos, 1967.

MARTINS, Denise A. C. Aspectos do baby talk no português. Diss. mestrado, PUCRJ, 1977.

. Mecanismo de simplificação em registros especiais do português. Tese de doutorado, UFRJ, 1990.

MUFWENE, Salikoko. La créolisation en bantou: les cas du kituba, du lingala urbain, et du swahili du Shaba. Etudes créoles XII,1.74-106, 1989.

MÜHLHÄUSLER, Peter. Pidgin and creole linguistics. Oxford: Blackwell, 1986.

NARO, Anthony J. On the origins of pidginization. Language 54(2).314-349, 1978.

REINECKE, John E. Marginal languages: A sociohistorical survey of the creole languages and trade jargons. Ph. D. Diss., Yale University, 1937.

ROBERTS, Peter A. Problems with similarities across creoles and the development of creole. The behavioral and brain sciences 7(2).205-206, 1984.

SAUSSURE, Ferdinand. Curso de lingüistica geral. São Paulo: Cultrix, 5a. ed., 1973.

SCHUCHARDt, Hugo. Die Lingua Franca. Zeitschrift für romanische Philologie XXXIII.441-461, 1909.

SLOBIN, Dan. Psicolingüistica. São Paulo: Companhia Editora Nacional e EDUSP, 1980.

STOEL-GAMMON, Caroline. Baby talk in Brazilian Portuguese. Revista Brasileira de Lingüistica II (1). 22-26, 1976.

TEYSSIER, Paul. História da lingua portuguesa. Lisboa: Sá da Costa, 1987.

THOMASON, Sarah G. \& KAUFMAN, Terrence. Language contact, creolization, and genetic linguistics. Berkeley: University of California Press, 1988.

TODD, Loreto. Pidgins and creoles. Londres: Routledge, $2^{\underline{\underline{a}}}$ ed., 1990.

VALDMAN, Albert. Créolisation sans pidgin: Le système des determinants du nom dans les parlers franco-créoles. In: Meisel, J. (org): 105-136, 1977.

WANG, William S. Y. Organum ex-machina? The behavioral and brain sciences 7(2).210-211, 1984. 